\title{
Pengembangan buku ajar fisika berbasis kearifan lokal siswa di Kelas X SMA
}

\section{Retno Nurmaya Sari}

Program Studi Pendidikan Fisika, IKIP PGRI Pontianak, Indonesia

Surat-e: sarinurmaya111@gmail.com

\section{Dwi Fajar Saputri}

Program Studi Pendidikan Fisika, IKIP PGRI Pontianak, Indonesia Surat-e: dfsaputri20@gmail.com

\section{Matsun ${ }^{1}$}

Program Studi Pendidikan Fisika, IKIP PGRI Pontianak, Indonesia Surat-e: matsunzaidan@gmail.com

\begin{abstract}
Abstrak. Penelitian yang dilakukan didasari oleh belum adanya Buku Ajar Fisika Berbasis Kearifan Lokal di SMA Negeri 01 Seponti. Oleh karena itu, penelitian ini bertujuan untuk mengembangkan Buku Ajar Fisika Berbasis Kearifan Lokal di SMA Negeri 01 Seponti. Secara khusus penelitian ini bertujuan untuk mengetahui kelayakan dan respon siswa terhadap Buku Ajar Fisika Berbasis Kearifan Lokal di SMA Negeri 01 Seponti. Metode penelitian yang digunakan yaitu metode penelitian dan pengembangan (R\&D) dengan menggunakan model 4D (Four D Models) yang terdiri dari empat tahap, yaitu tahap pendefinisian (define), tahap perancangan (design), tahap pengembangan (develop), dan tahap penyebaran (disseminate). Instrument yang digunakan yaitu instrument berupa angket validasi menggunakan skala likert dengan rentang skor 1-4. Berdasarkan hasil analisis data diketahui bahwa Buku Ajar Fisika Berbasis Kearifan Lokal di SMA Negeri 01 Seponti memiliki hasil validasi untuk ahli materi dengan skor rata-rata 78,75\% dan validasi ahli media dengan skor rata-rata 77,27\% dengan kategori sangat layak. Respon siswa memiliki skor $76 \%$ dengan kategori sangat baik. Kelebihan dari buku ajar yang dikembangkan yaitu memuat kontensehari-hari yang ada di daerah siswa tinggal sehingga mudah dalam memahami konsep fisika.
\end{abstract}

Kata kunci: pengembangan, buku ajar fisika, kearifan lokal

\begin{abstract}
The research carried out was based on the absence of a Physics Textbook based on Local Wisdom at SMA Negeri 01 Seponti. Therefore, this study aims to develop a Physics Textbook based on Local Wisdom at SMA Negeri 01 Seponti. Specifically, this study aims to determine the feasibility and response of students to Physics Textbooks Based on Local Wisdom at SMA Negeri 01 Seponti. The research method used is the research and development (R\&D) method using the 4-D model (FourD Models) which consists of four stages, namely the define stage, the design stage, the develop stage, and the deployment stage. (disseminate). The instrument used was an instrument in the form of a validation questionnaire using a Likert scale with a score range of 1-4. Based on the results of data analysis, it is known that the Physics Textbook Based on Local Wisdom at SMA Negeri 01 Seponti has validation results for material experts with an average score of $78.75 \%$ and validation of media experts with an average score of $77.27 \%$ with a very feasible category. Student response has a score of $76 \%$ in the very good category. The advantages of the developed textbooks are that they contain everyday content that is in the area where students live so that it is easy to understand the concepts of physics.
\end{abstract}

Keywords: development, physics textbook, local wisdom

\footnotetext{
${ }^{1}$ Corresponding Author
} 


\section{Pendahuluan}

Pembelajaran fisika sebaiknya dilakukan dengan proses yang menarik dan menyenangkan, mengingat pembelajaran fisika merupakan kegiatan mempelajari ilmu pengetahuan tentang gejala alam dan sekitar siswa. Fisika adalah ilmu yang mempelajari tentang alam dan isinya gejala-gejala yang terjadi didalamnya, sehingga pendidikan fisika diharapkan bisa dijadikan sebagai sarana atau tempat bagi siswa untuk bisa menerapkan dalam kehidupan sehari-hari. Pembelajaran fisika mempunyai arti penting sebagai faktor dalam pengetahuan alam yang dapat memberikan peluang untuk mengembangkan kekuatan mental dan daya fikir sehingga dengan mempelajari fisika siswa dapat berfikir masuk akal (logis) [1]. Untuk menghubungkan kearifan lokal dengan materi pelajaran fisika dalam dunia pendidikan maka diperlukan suatu bahan ajar yang dapat menjebataninya. Salah satunya adalah bahan ajar berupa buku. Buku merupakan media cetak yang sengaja dirancang secara sistematis dan bertujuan supaya dapat digunakan oleh peserta didik dalam kegiatan pembelajaran. Buku dibuat menyesuaikan dengan karakteristik peserta didik. Hal ini dilakukan agar dengan adanya buku tersebut peserta didik dapat dengan mudah memahami dan belajar secara mandiri [2].

Kearifan lokal merupakan suatu pandangan hidup, ilmu pengetahuan dan berbagi strategi kehidupan yang terwujud dalam aktivitas masyarakat lokal untuk menjawab berbagai masalah pemenuhan kebutuhan anggota masyarakat tersebut. Kearifan lokal juga didefinisikan sebagai bentuk kekayaan setempat atau suatu daerah berupa, kepercayaan, pengetahuan, norma, kebudayaan, adat istiadat, wawasan, dan lain sebagainya yang diwariskan dan dipertahankan sehingga menjadi sebuah identitas dan pedoman untuk mengajarkan cara bertindak secara dapat dalam menjalani kehidupan [3].

Berdasarkan hasil wawancara dengan guru fisika SMA Negeri 01 Seponti, ditemukan bahwa belum adanya bahan ajar fisika seperti buku fisika yang berintegrasi pada kearifan lokal, masalah waktu yang kurang memadai untuk menyampaikan teori dan praktek serta kurang didukung dengan alat dan media yang memadai, selain itu banyaknya materi yang harus di sampaikan dan waktu yang terbatas. Siswa kurang termotivasi dalam melakukan kegiatan pembelajaran fisika di sekolah. Hal ini diketahui ketika para siswa disuruh menjawab beberapa pertanyaan wawancara. Mereka kurang tertarik terhadap bahan ajar yang telah ada. Kerumitan bahan ajar yang disampaikan semakin membuat siswa kurang tertarik untuk membaca buku ajar fisika. Hal ini dikarenakan banyaknya materi yang disampaikan, waktu yang terbatas pada pembelajaran fisika, kesulitan dalam materi yang kurang dipahami pada pembelajaran yang berlangsung dan kesulitan dalam memahami rumus-rumus fisika. Penggunaan buku fisika kearifan lokal efektif dalam proses pembelajaran. Permasalahan utama dalam penelitian ini adalah sekolah masih belum mempunyai buku fisika yang terdapat konten kearaifan lokal siswa di daerah Seponti, dengan harapan siswa lebih mudah dan termotifasi dalam belajar fisika di kelas. Dengan hal tersebut dilakukanlah penelitian dengan judul "Pengembangan buku fisika berbasis kearifan lokal" Dalam pembelajaran fisika, belajar dan latihan soal merupakan kewajiban bagi setiap siswa dan buku merupakan sumber belajar yang paling umum digunakan dalam kegiatan belajar siswa. Ketika siswa membuka sebuah buku pelajaran yang ditemukan adalah halaman yang penuh dengan deretan tulisan kecil, dan juga terlihat gambar dan diagram yang sulit untuk dipahami, semua itu tersusun dengan tata letak yang kaku dan membuat sedikit banyak siswa tidak berminat membuka buku tersebut, apa lagi untuk membacanya. Kerumitan bahan ajar yang disampaikan semakin membuat siswa kurang tertarik membaca buku ajar.

Buku ajar fisika peserta didik berbasis kearifan lokal menempati posisi strategis dalam pembelajaran untuk meningkatkan karakter dan ketuntasan belajar peserta didik. Hal ini cukup beralasan karena melalui buku sejumlah materi fisika dapat dimuat, utamanya materi-materi pelajaran yang tidak dapat disajikan secara nyata atau abstrak. Selain itu, pada buku fisika peserta didik dapat disisipkan muatan-muatan karakter yang berbasis kearifan lokal. Sehingga karekter dan ketuntasan belajar peserta didik dapat meningkat. Keberadaan buku fisika peserta didik semakin memperkuat makna pendidik sebagai proses transformasi nilai-nilai budaya disamping hakikat budaya disamping hakikat fisika sebagai mata pelajaran.oleh karena itu, pendidik mata pelajaran fisika yang melaksanakan tugas profesiaonalnya pada suatu lingkungan masyarakat, khusus diwilayah kabupaten Kayong Utara harus mampu menjadikan kearifan lokal yang ada sebagai basis dalam pengembangan buku fisika peserta didik yang kelak digunakan dalam pelaksanaan pembelajaran.

\section{Metode Penelitian}

Penelitian yang dilaksanakan adalah penelitian pengembangan atau Research and Development. Penelitian ini mengembangkan Buku Ajar Fisika Berbasis Kearifan Lokal di SMA Negeri 01 Seponti. Model pengembangan yang digunakan adalah model 4-D model dengan langkah-langkah define (pendefinisian), design 
(perancangan), development (pengembangan), dan desiminate (penyebaran). Subjek penelitian ini berjumlah 2 orang dosen dan 2 orang guru SMA Negeri 01 Seponti dengan responden uji coba berjumlah 25 siswa. Uji coba produk dilakukan pada siswa SMA Negeri 01 Seponti kelas X. Langkah-langkah pengembangan Buku Ajar Fisika Berbasis Kearifan Lokal di SMA Negeri 01 Seponti melalui tahapan yang di sesuaikan dengan tahapan pada pengembangan 4-D models.

Pengumpulan data penelitian menggunakan beberapa instrument yaitu lembar validasi produk yang mencakup aspek penyajian, kelayakan isi, dan Bahasa. Untuk mengetahui respon siswa terhadap Buku Ajar Fisika Berbasis Kearifan Lokal di SMA Negeri 01 Seponti digunakanlah lembar respon.

Mengenai tanggapan ahli materi dan ahli media terhadap pengembangan bahan ajar berbentuk Buku Ajar Fisika Berbasis Kearifan Lokal digunakan angket respon ahli dengan menghitung presentase kelayakan media pembelajaran berdasarkan skor yang diperoleh menggunakan persamaan [4]

$$
P=\frac{\text { skor yang diperoleh }}{\text { skor maksimum }} \times 100 \%
$$

Selanjutnya memberikan kriteria dasar pengambilan keputusan berdasarkan tabel 1 yaitu dengan memodifikasi dari jurnal Avisha Puspita, dkk.

Tabel 1. Kriteria kelayakan buku ajar

\begin{tabular}{ccc}
\hline No & Prosentase (\%) & Kriteria kelayakan \\
\hline 1 & $76-100$ & Sangat layak \\
2 & $51-75$ & Layak \\
3 & $26-50$ & Tidak layak \\
4 & $0-25$ & Sangat tidak layak \\
\hline
\end{tabular}

Mengenai respon siswa terhadap pengembangan modul fisika berbasis kearifan lokal digunakan angket respon siswa dengan cara mentransformasi skor tiap-tiap yang diamati kedalam kalimat yang bersifat kuantitatif menggunakan skala Likert dengan rumus:

$$
\% N R S=\frac{\sum N R S}{N R S_{\max }} \times 100 \%
$$

Tabel 2. Kriteria respon siswa

\begin{tabular}{ccc}
\hline No & Prosentase (\%) & Kriteria kelayakan \\
\hline 1 & $76-100$ & Sangat baik \\
2 & $51-75$ & Baik \\
3 & $26-50$ & Tidak baik \\
4 & $0-25$ & Sangat tidak baik \\
\hline
\end{tabular}

\section{Hasil Penelitian dan Pembahasan}

Pengembangan Buku Ajar Fisika Berbasis Kearifan Lokal terdiri dari empat tahapan yaitu tahap pendefinisian (define), tahap perancangan (design), tahap pengembangan (develop) dan tahap penyebaran (desseminate).

\section{Pendefinisian (Define)}

Tahap pendefinisian dilakukan untuk mengidentifikasi kebutuhan berdasarkan permasalahan yang ditemukan. Adapun langkah-langkah yang dilakukan dalam tahap pendefinisian yang pertama Analisis Awalakhir. Pada tahapan ini langkah pertama yang dilakukan peneliti adalah menentukan masalah. Setelah mengidentifikasi masalah yang dialami siswa maka peneliti menentukan solusi yang akan ditawarkan. Saat melaksanakan tahap ini peneliti melakukan wawancara terhadap guru mata pelajaran fisika. Wawancara dilaksanakan pada tanggal 4 Februari 2020 diruang kantor guru. Wawancara ini bertujuan untuk menganalisis masalah yang dialami siswa dan apa saja penyebab dari permasalahan tersebut. Hal-hal yang ditanyakan antara lain terkait siswa, materi pelajaran dan media pembelajaran. Tahapan yang kedua adalah Analisis Siswa. Dalam wawancara yang dilakukan saat itu, peneliti menanyakan 10 butir pertanyaan kepada guru fisika. 
Sebelum melakukan wawancara peneliti mengucapkan salam terlebih dahulu, kemudian dilanjutkan dengan pertanyaan. Yang terakhir Analisis Tugas. Berdasarkan hasil wawancara, guru menyimpulkan bahwa masih banyak siswa yang mengalami kesulitan dalam belajar dikarenakan buku ajar yang ada di sekolah memuat banyak materi sehingga siswa cepat merasa bosan dengan pembelajaran yang dilakukan guru. Oleh karena itu peneliti menawarkan untuk mengembangkan buku ajar berbasis kearifan lokal berisi materi yang dikaitkan dalam kehidupan sehari-hari yang ada di daerah seponti agar siswa tertarik belajar fisika.

\section{Perancangan (Design)}

Tahapan perancangan dilakukan untuk merancang produk yang dikembangkan dan disesuaikan dengan permasalahan yang diperoleh dilapangan pada tahap pendefinisian. Pada tahap ini, penulis menyusun instrumen untuk menilai kelayakan Buku ajar fisika berbasis kearifan lokal [5]. Penyusunan instrumen penelitian ini dibagi menjadi dua langkah yaitu: Pada langkah pertama, peneliti menyusun kisi-kisi lembar validasi baik ahli materi maupun ahli media dan kisi-kisi angket respon siswa. Kisi-kisi lembar validasi ahli materi disusun dengan 2 aspek yaitu, aspek cakupan materi ( 4 butir pernyataan), aspek akurasi materi ( 6 butir pernyataan). Sedangkan kisi-kisi lembar validasi ahli media disusun dengan 8 aspek yaitu, aspek tampilan (3 butir pernyataan), aspek komunikatif (1 butir pernyataan), aspek koherensi dan keruntutan alur (1 butir pernyataan), aspek kesesuaian dengan kaidah bahasa indonesia yang benar ( 1 butir pernyataan), aspek penggunaan istilah dan simbol (1 butir pernyataan), aspek teknik penyajian (1 butir pernyataan), aspek penyajian pembelajaran ( 2 butir pernyataan), aspek pendukung penyajian ( 1 butir pernyataan). Pada langkah kedua, peneliti menyusun lembar validasi dan angket respon siswa sesuai dengan kisi-kisi yang telah dibuat pada langkah pertama. Butir pernyataan yang di peroleh dari ahli materi 10 butir pernyataan dan ahli media 11 butir pernyataan. Sedangkan angket respon siswa sebanyak 16 butir pernyataan. Selanjutnya merancang Buku Ajar Fisika Berbasis Kearifan Lokal. Adapun spesifikasi produk yang dikembangkan dalam penelitian ini dapat dilihat pada tabel 3.

Tabel 3. Spesifikasi Produk

\begin{tabular}{|c|c|c|}
\hline No & $\begin{array}{c}\text { Bagian-bagian buku yang } \\
\text { dikembangkan }\end{array}$ & Tampilan buku yang dikembangkan \\
\hline 1. & Cover depan & Berupa kekhasan lokal yang ada di daerah wilayah tersebut \\
\hline 2. & Halaman judul & $\begin{array}{l}\text { Berupa pengulangan dari judul dan nama pengarangnya yang telah ada } \\
\text { di cover depan }\end{array}$ \\
\hline 3. & Impresum & $\begin{array}{l}\text { Berisikan informasi tentang buku seperti ukuran, jumlah halaman, } \\
\text { penerbit, nama editor dll }\end{array}$ \\
\hline 4. & Halaman persembahan & Berupa pengucapan penulis kepada pihak tertentu yang istimewa \\
\hline 5. & Daftar isi & Berupa isi susunan bab dan halaman secara keseluruhan \\
\hline 6. & Kata pendahuluan & Berupa garis besar tentang buku \\
\hline 7. & Kata pengantar & Berupa isi sapaan penuliskepada pembaca \\
\hline
\end{tabular}




\begin{tabular}{lll}
\hline No & $\begin{array}{c}\text { Bagian-bagian buku yang } \\
\text { dikembangkan }\end{array}$ & \multicolumn{1}{c}{ Tampilan buku yang dikembangkan } \\
\hline 8. & Isi buku & $\begin{array}{l}\text { Berupa pendahuluan yang berisi tentang kearifan lokal, kompetensi } \\
\text { dasar, materi, contoh soal, latihan soal, tugas mandiri kelompok, dan } \\
\text { rangkuman }\end{array}$ \\
\hline 9. & Daftar pustaka & Berupa daftar referensi dalam penulisan \\
\hline 10. & Biodata penulis & Berupa riwayat singkat tentang perjalanan hidup penulis \\
\hline $11 .$. & Glosarium & $\begin{array}{l}\text { Berupa sebagai daftar bentuk abjad yang terangkum dalam sebuah } \\
\text { buku }\end{array}$ \\
\hline 12. & Cover belakang & Berupa cuplikan isi buku atau pengantar penulis terhadap buku tersebut \\
\hline
\end{tabular}

\section{Pengembangan (Develop)}

Tahap pengembangan (develop) bertujuan untuk mengembangkan produk yang telah dirancang mulai dari validasi oleh para ahli, sampai dengan produk akhir [6]. Dalam hal ini peneliti juga melakukan perbaikan terhadap buku ajar sehingga menghasilkan buku ajar baru yang telah direvisi. Adapun bagian-bagian yang harus diperbaiki berdasarkan masukan dari para ahli antara lain. Sebelum direvisi oleh ahli pada kata pengantar terdapat kalimat "Oleh karena itu" yang dianggap tidak sesuai dengan kalimat sebelumnya (gambar 1.a). Selain itu, kata" bahan ajar" harus diganti. Setelah direvisi kata-kata pada kata pengantar menjadi lebih tertata dan jelas (gambar 1.b).

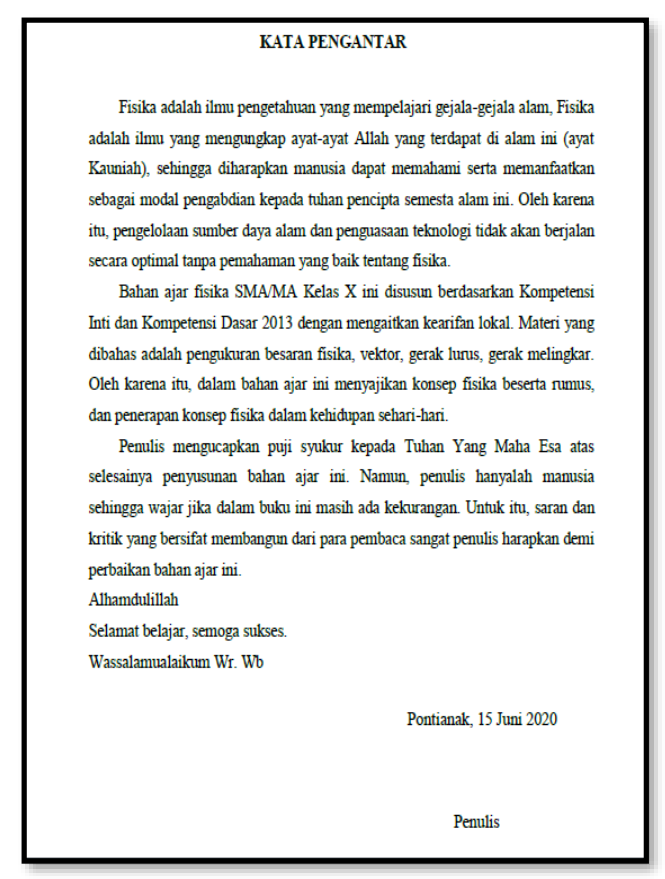

(a)

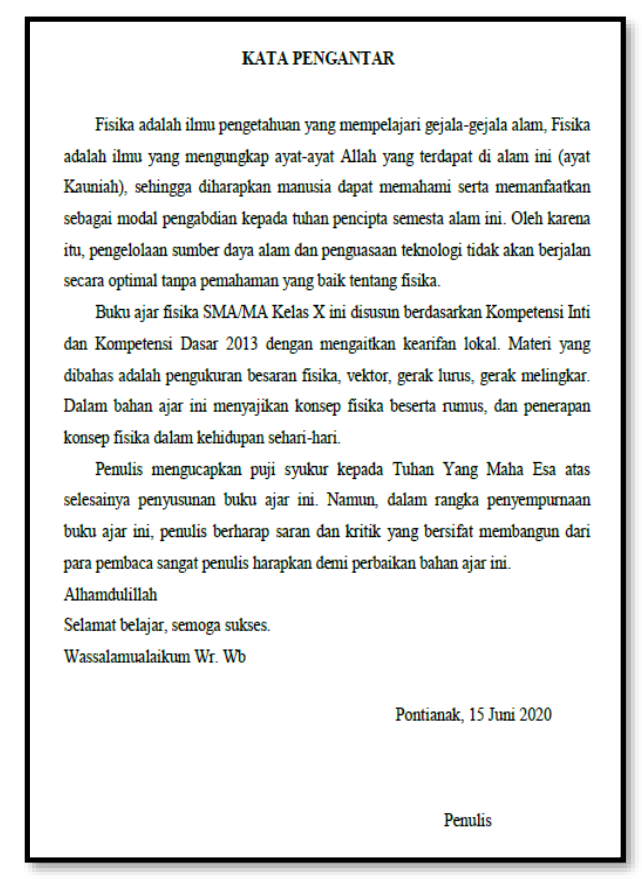

(b)

Gambar 1. (a) sebelum direvisi, (b) setelah direvisi

Sebelum direvisi oleh ahli pada kata "perhatikan gambar di atas" perlu di tambahkan kata "gambar 1.1" (perhatikan gambar 2.a. Setelah direvisi oleh ahli materi menjadi "perhatikan gambar 1.1 di atas" (gambar 2.b.). 


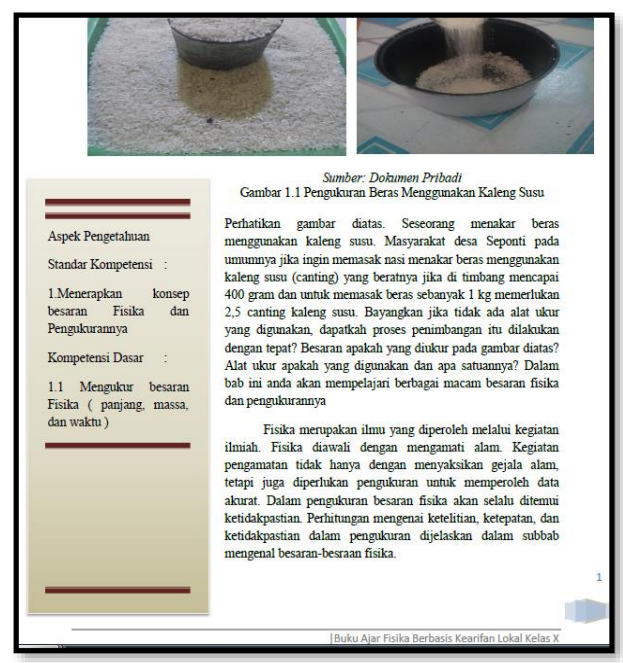

(a)

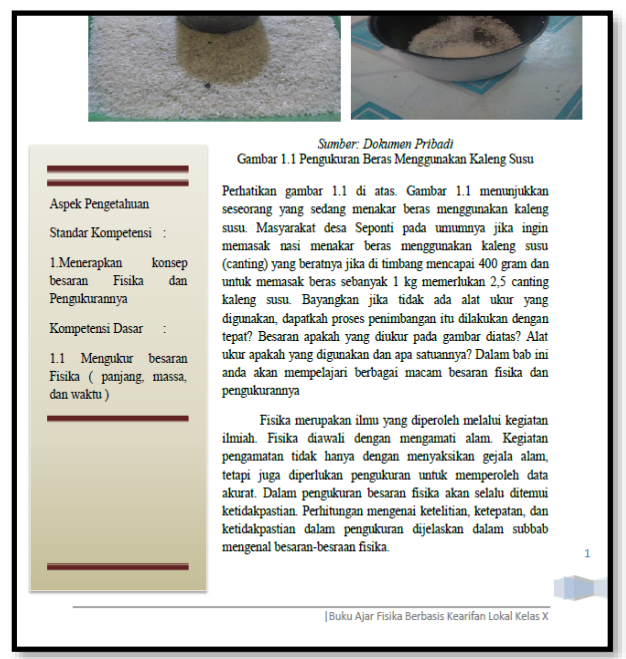

(b)

Gambar 2. (a) sebelum direvisi, (b) setelah direvisi

Tabel 4. Revisi Soal Evaluasi Bab I

\begin{tabular}{|c|l|l|}
\hline Hasil & \multicolumn{1}{|c|}{ Sebelum Revisi } & \multicolumn{1}{|c|}{ Setelah Revisi } \\
\hline 4 & Seorang calon penumpang menunggu bis selama & Siswa SMA Negeri 01 Seponti akan pergi studi \\
& 30 menit. Berdasarkan pernyataan tersebut, yang & tour ke pulau datuk mereka menunggu bis \\
& menunjukkan satuan yaitu .... & selama 30 menit. Berdasarkan pernyataan \\
& a. 30 menit & tersebut, yang menunjukkan satuan yaitu .... \\
& b. siswa & a. 30 menit \\
& c. 30 & b. siswa \\
& d. bus & c. 30 \\
& e. Menit & d. bus \\
\hline 11 & Hasil pengukuran tebal buku tulis menggunakan & e. Menit \\
& jangka sorong yaitu 5,24 mm., Pembacaan dari & Guru fisika SMA Negeri 01 Seponti memberikan \\
& hasil pengukuran tersebut dengan & tugas kepada siswa untuk melakukan pengukuran \\
& memperhitungkan kesalahan mutlak dapat & terhadap tebal buku tulis. Hasil pengukuran tebal \\
& dituliskan menjadi .... & buku tulis menggunakan jangka sorong yaitu \\
& a. $(5,24+1) \mathrm{mm}$ & 5,24 mm., Pembacaan dari hasil pengukuran \\
& b. $(5,24+0,01) \mathrm{mm}$ & tersebut dengan memperhitungkan kesalahan \\
& c. $(5,24+0,1) \mathrm{mm}$ & mutlak dapat dituliskan menjadi .... \\
& d. $(5,24+0,05) \mathrm{mm}$ & a. $(5,24+1) \mathrm{mm}$ \\
& e. $(5,24+0,5) \mathrm{mm}$ & b. $(5,24+0,01)$ mm \\
& & c. $(5,24+0,1) \mathrm{mm}$ \\
& d. $(5,24+0,05)$ mm \\
& e. $(5,24+0,5) \mathrm{mm}$ \\
\hline
\end{tabular}

Sebelum direvisi oleh ahli pada tampilan gambar orang menarik sapi, gambar tersebut dianggap kurang menarik karna ukurannya terlalu lebar (gambar 5.a.). Setelah direvisi oleh ahli pada tampilan gambar orang menarik sapi ukurannya diperkecil sehingga gambarnya lebih menarik (gambar 5.b.). 


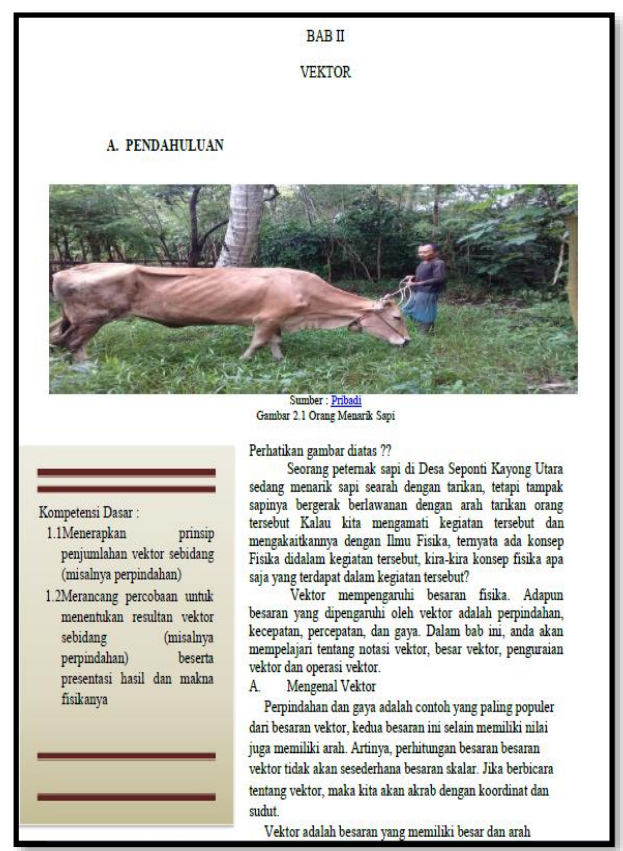

(a)

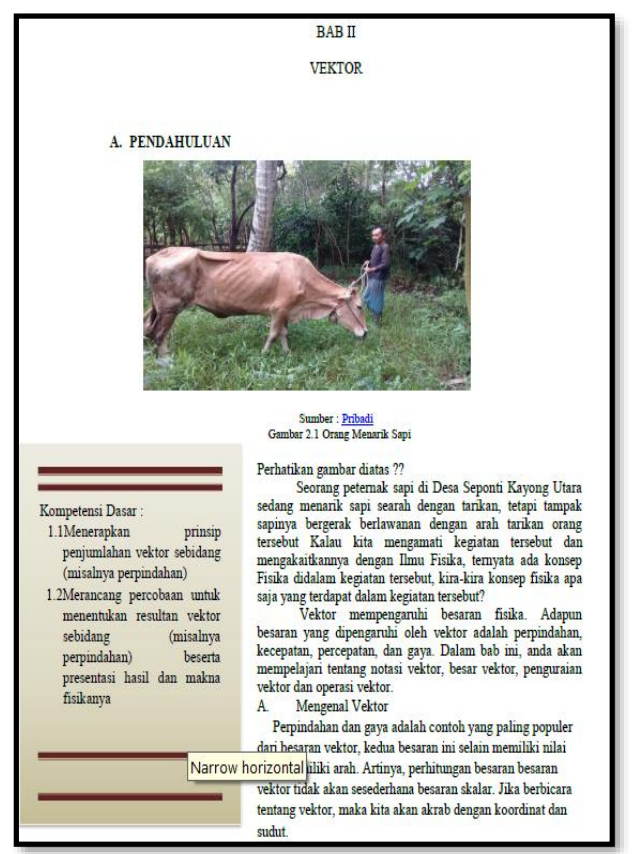

(b)

Gambar 3. (a) sebelum direvisi, (b) setelah direvisi

Tabel 5. Revisi Soal Evaluasi Bab II

\begin{tabular}{|c|l|l|}
\hline Hasil & \multicolumn{1}{|c|}{ Sebelum Revisi } & \multicolumn{1}{c|}{ Setelah Revisi } \\
\hline 4 & Pada perlombaan tarik tambang, kelompok A & Pada perayaan 17 agustus warga seponti \\
& menarik ke arah timur dengan gaya 700 N. & melakukan perlombaan tarik tambang, kelompok \\
& Kelompok B menarik ke barat dengan gaya 665 & A menarik ke arah timur dengan gaya 700 N. \\
& N. Kelompok yang memenangi perlombaan & Kelompok B menarik ke barat dengan gaya 665 \\
& adalah kelompok... & N. Kelompok yang memenangi perlombaan \\
& a. A dengan resultan gaya 25 N & adalah kelompok .... \\
& b. A dengan resultan gaya 35 N & a. A dengan resultan gaya 25 N \\
& c. B dengan resultan gaya 25 N & b. A dengan resultan gaya 35 N \\
& d. B dengan resultan gaya 35 N & c. B dengan resultan gaya 25 N \\
& e. B dengan resultan gaya 45 N & d. B dengan resultan gaya 35 N \\
& & e. B dengan resultan gaya 45 N \\
\hline
\end{tabular}

Sebelum direvisi oleh ahli pada tampilan gambar sebuah kapal penumpang, gambar tersebut dianggap kurang menarik karna ukurannya terlalu lebar (gambar 4.a.). Setelah direvisi oleh ahli pada tampilan gambar sebuah kapal penumpang ukurannya diperkecil sehingga gambarnya lebih menarik (gambar 4.b.). 


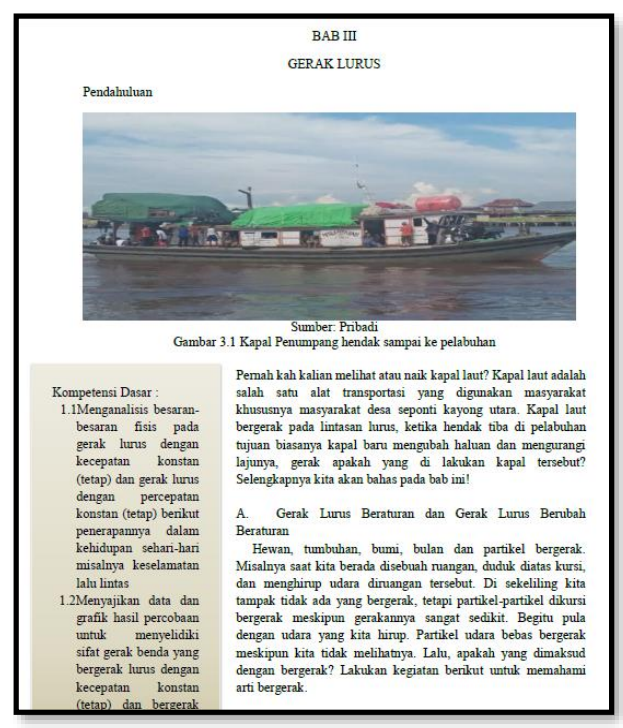

(a)

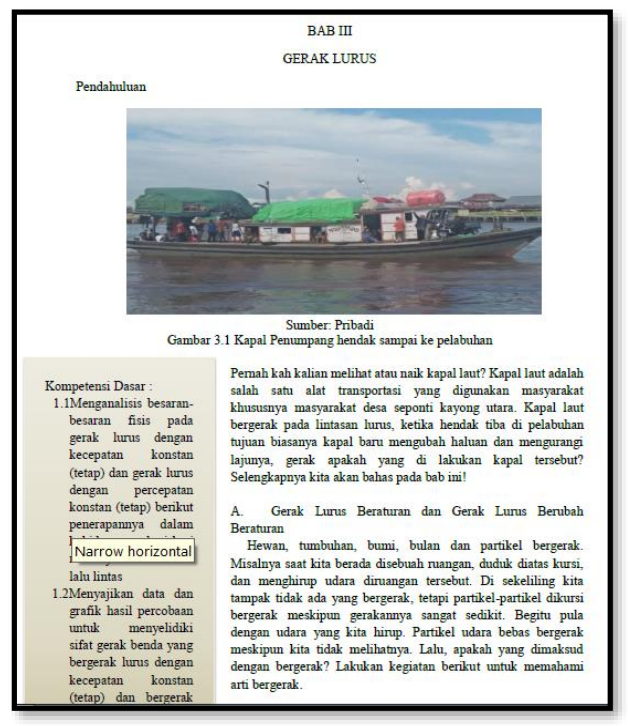

(b)

Gambar 4. (a) sebelum direvisi, (b) setelah direvisi

Tabel 6. Revisi Soal Evaluasi Bab III

\begin{tabular}{|c|c|c|}
\hline Hasil & Sebelum Revisi & Setelah Revisi \\
\hline 4 & $\begin{array}{l}\text { Seseorang memacu sepeda motor dari rumahnya } \\
\text { ke arah utara sejauh } 6 \mathrm{~km} \text {, lalu berbelok ke timur } \\
\text { sejauh } 8 \mathrm{~km} \text {. Posisi orang tersebut dari rumahnya } \\
\text { setelah melakukan perjalanan tersebut adalah .... } \\
\text { A. } 2 \mathrm{~km} \text { ke arah timur } \\
\text { B. } 14 \mathrm{~km} \text { ke arah timur laut } \\
\text { C. } 14 \mathrm{~km} \text { ke arah barat daya } \\
\text { D. } 10 \mathrm{~km} \text { ke arah timur laut } \\
\text { E. } 10 \mathrm{~km} \text { ke arah barat daya }\end{array}$ & $\begin{array}{l}\text { Seorang petani di desa seponti yang akan pergi } \\
\text { ke sawah memacu sepeda motor dari rumahnya } \\
\text { ke arah utara sejauh } 6 \mathrm{~km} \text {, lalu berbelok ke timur } \\
\text { sejauh } 8 \mathrm{~km} \text {. Posisi petani tersebut dari } \\
\text { rumahnya setelah melakukan perjalanan tersebut } \\
\text { adalah .... } \\
\text { A. } 2 \mathrm{~km} \text { ke arah timur } \\
\text { B. } 14 \mathrm{~km} \text { ke arah timur laut } \\
\text { C. } 14 \mathrm{~km} \text { ke arah barat daya } \\
\text { D. } 10 \mathrm{~km} \text { ke arah timur laut } \\
\text { E. } 10 \mathrm{~km} \text { ke arah barat daya }\end{array}$ \\
\hline 6 & $\begin{array}{l}\text { Sebuah batu kecil dilempar ke atas dan mendarat } \\
\text { di sebuah papan yang terletak } 2 \mathrm{~m} \text { di atas titik } \\
\text { pelemparan. Jika kecepatan awal batu dilempar } \\
\text { ke atas adalah } 7 \mathrm{~m} / \mathrm{s} \text {, kecepatan batu ketika } \\
\text { mengenai sasaran adalah .... } \\
\text { A. } 0 \mathrm{~m} / \mathrm{s} \\
\text { B. }-3 \mathrm{~m} / \mathrm{s} \\
\text { C. } 3 \mathrm{~m} / \mathrm{s} \\
\text { D. } 3,4 \mathrm{~m} / \mathrm{s} \\
\text { E. } 4 \mathrm{~m} / \mathrm{s}\end{array}$ & $\begin{array}{l}\text { Siswa SMA Negeri } 01 \text { Seponti melakukan } \\
\text { eksperimen dengan melempar sebuah batu kecil } \\
\text { ke atas dan mendarat di sebuah papan yang } \\
\text { terletak } 2 \mathrm{~m} \text { di atas titik pelemparan. Jika } \\
\text { kecepatan awal batu dilempar ke atas adalah } 7 \\
\text { m/s, kecepatan batu ketika mengenai sasaran } \\
\text { adalah ... } \\
\text { A. } 0 \mathrm{~m} / \mathrm{s} \\
\text { B. }-3 \mathrm{~m} / \mathrm{s} \\
\text { C. } 3 \mathrm{~m} / \mathrm{s} \\
\text { D. } 3,4 \mathrm{~m} / \mathrm{s} \\
\text { E. } 4 \mathrm{~m} / \mathrm{s}\end{array}$ \\
\hline 10 & $\begin{array}{l}\text { Budi dan Badu adalah dua sahabat yang sangat } \\
\text { akrab. Mereka adalah mahasiswa perantauan } \\
\text { yang sedang menuntut ilmu di suatu kampus } \\
\text { ternama. Pada hari lebaran Budi dan Badu } \\
\text { berencana pulang kampung. Jika kampung budi } \\
\text { dapat ditempuh dengan Bus selama } 2 \text { jam dengan } \\
\text { yang memiliki kecepatan tetap } 80 \mathrm{~km} / \mathrm{jam} \text {. } \\
\text { Berapa jam yang diperlukan untuk sampai di } \\
\text { kampung Badu jika jaraknya ditambah } 320 \mathrm{~km} \\
\text { lagi. }\end{array}$ & $\begin{array}{l}\text { Budi dan Badu adalah dua sahabat yang sangat } \\
\text { akrab. Mereka adalah mahasiswa perantauan } \\
\text { yang sedang menuntut ilmu di suatu kampus } \\
\text { ternama. Pada hari lebaran Budi dan Badu } \\
\text { berencana pulang kampung. Jika kampung budi } \\
\text { dapat ditempuh dengan Bus selama } 2 \text { jam dengan } \\
\text { yang memiliki kecepatan tetap } 80 \mathrm{~km} / \mathrm{jam} \text {. } \\
\text { Berapa jam yang diperlukan untuk sampai di } \\
\text { kampung Badu jika jaraknya ditambah } 320 \mathrm{~km} \\
\text { lagi . }\end{array}$ \\
\hline
\end{tabular}




\begin{tabular}{|c|c|c|}
\hline Hasil & Sebelum Revisi & Setelah Revisi \\
\hline & $\begin{array}{l}\text { A. } 6 \text { jam } \\
\text { B. } 4 \text { jam } \\
\text { C. } 2 \text { jam } \\
\text { D. } 3 \text { jam }\end{array}$ & $\begin{array}{l}\text { A. } 6 \text { jam } \\
\text { B. } 4 \text { jam } \\
\text { C. } 2 \text { jam } \\
\text { D. } 3 \text { jam }\end{array}$ \\
\hline 11 & $\begin{array}{l}\text { Bu Dini adalah seorang guru di Sekolah Dasar. } \\
\text { Tentunya Bu Dini harus menjaga waktunya agar } \\
\text { tidak telat sampai di Sekolah. Jika jarak rumah } \\
\text { Bu Dini dengan Sekolah adalah } 18 \mathrm{~km} \text {. Dan Bu } \\
\text { Dini hanya bisa mengendarai mobilnya dengan } \\
\text { pelan kecepatannya } 36 \mathrm{~km} / \mathrm{jam} \text {. Sedangkan jam } \\
\text { Sekolah masuknya pada pukul } 07.00 \text {. Pada pukul } \\
\text { berapa agar bu Dinir harus berangkat ke Sekolah } \\
\text { agar tidak telat? } \\
\text { A. } 06.20 \\
\text { B. } 06.40 \\
\text { C. } 06.44 \\
\text { D. } 06.50\end{array}$ & $\begin{array}{l}\text { Bu Dini adalah seorang guru di SMA Negeri } 01 \\
\text { Seponti. Tentunya Bu Dini harus menjaga } \\
\text { waktunya agar tidak telat sampai di Sekolah. Jika } \\
\text { jarak rumah Bu Dini dengan Sekolah adalah } 18 \\
\text { km. Dan Bu Dini hanya bisa mengendarai } \\
\text { mobilnya dengan pelan kecepatannya } 36 \mathrm{~km} / \mathrm{jam} \text {. } \\
\text { Sedangkan jam Sekolah masuknya pada pukul } \\
\text { 07.00. Pada pukul berapa agar bu Dinir harus } \\
\text { berangkat ke Sekolah agar tidak telat? } \\
\text { A. } 06.20 \\
\text { B. } 06.40 \\
\text { C. } 06.44 \\
\text { D. } 06.50\end{array}$ \\
\hline 12 & $\begin{array}{l}\text { Jarak kota Banda Aceh ke kota Medan adalah } \\
420 \mathrm{~km} \text {. Jarak tersebut dapat ditempuh dalam } \\
\text { waktu } 7 \text { jam. Tentukanlah waktu yang } \\
\text { diperlukan mobil tersebut untuk mencapai kota } \\
\text { Pekanbaru yang memiliki jarak } 900 \mathrm{~km} \text { dari kota } \\
\text { Banda Aceh jika kecepatan yang digunakan } \\
\text { sama ketika mobil tersebut menempuh dari Kota } \\
\text { Banda Aceh menuju Meda. } \\
\text { A. } 9 \text { Jam } \\
\text { B. } 7 \text { Jam } \\
\text { C. } 15 \mathrm{Jam} \\
\text { D. } 20 \mathrm{Jam}\end{array}$ & $\begin{array}{l}\text { Jarak Desa Seponti ke Kabupaten Kayong adalah } \\
420 \mathrm{~km} \text {. Jarak tersebut dapat ditempuh dalam } \\
\text { waktu } 7 \text { jam. Tentukanlah waktu yang } \\
\text { diperlukan mobil tersebut untuk mencapai Pulau } \\
\text { Datuk yang memiliki jarak } 900 \text { km dari Desa } \\
\text { Seponti jika kecepatan yang digunakan sama } \\
\text { ketika mobil tersebut menempuh dari desa } \\
\text { Kayong menuju Kabupaten Kayong. } \\
\text { A. } 9 \text { Jam } \\
\text { B. } 7 \text { Jam } \\
\text { C. } 15 \text { Jam } \\
\text { D. } 20 \text { Jam }\end{array}$ \\
\hline
\end{tabular}

Sebelum direvisi oleh ahli pada tampilan gambar orang sedang bersepeda, gambar tersebut dianggap kurang menarik karna ukurannya terlalu lebar (gambar 5.a). Setelah direvisi oleh ahli pada tampilan gambar orang sedang bersepeda ukurannya diperkecil sehingga gambarnya lebih menarik (gambar 5.b.).

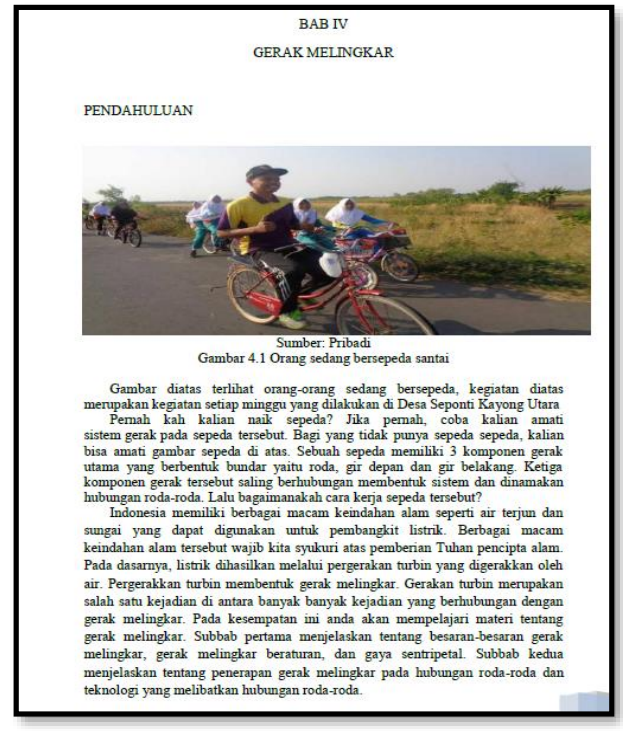

(a)

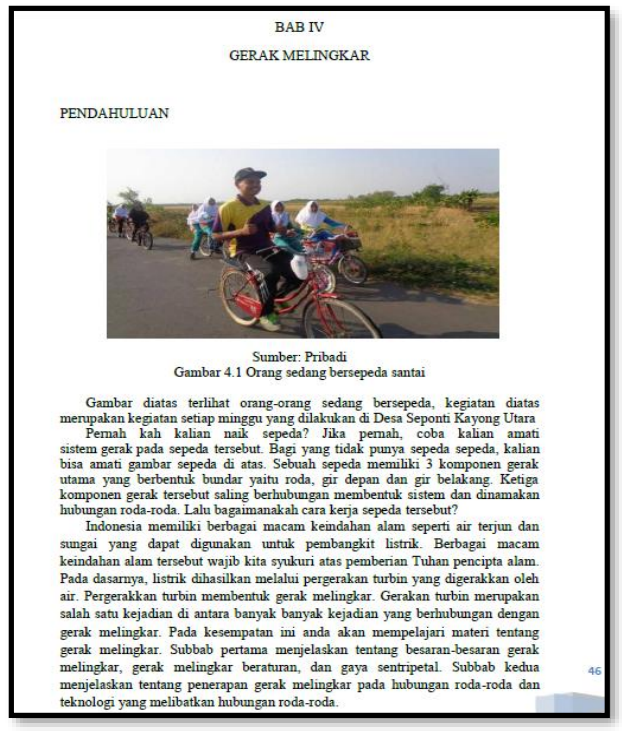

(b)

Gambar 5. (a) sebelum direvisi, (b) setelah direvisi 
Setelah diperoleh desain produk berupa bahan ajar, selanjutnya dilakukan validasi kepada ahli materi dan ahli media. Data hasil pengembangan Bahan Ajar Fisika pada Materi Pengukuran Berbasis Kearifan Lokal menurut ahli materi dan ahli media disajikan pada Tabel 7.

Tabel 7. Hasil Validasi Ahli Materi dan Ahli Media

\begin{tabular}{cccc}
\hline No & Bidang ahli & Prosentase $(\boldsymbol{\%})$ & Kriteria \\
\hline 1 & Ahli materi & 78,75 & Sangat layak \\
2 & Ahli media & 77,27 & Sangat layak \\
\hline
\end{tabular}

Berdasarkan tabel 7 diatas menunjukan bahwa validasi ahli materi dan media pada bahan ajar layak digunakan di dalam kelas. Hal ini sesuai dengan pendapat [7] yang menyatakn bahwa validitas mengacu pada tingkat kecukupan dan kelayakan terhadap interpretasi yang dibuat berdasarkan penilaian [8]. Suatu bahan ajar dinyatakan valid jika isi bahan ajar sesuai dengan kompetensi target belajar. Validasi bahan ajar menurut [9] merupakan suatu proses yang dilakukan untuk menguji kesesuiaan antara bahan ajar dengan kompetensi yang dijadikan sebagai target belajar.

Bahan ajar layak digunakan karena bahan ajar bahan ajar yang dikembangkan sudah memnuhi keteria dari aspek yang dinilai baik dari segi isi maupun tampilan bahan ajar. Hal ini sesuai dengan [10] untuk segi isi bahan ajar, bahan ajar yang dikembangkan harus dapat meningkatkan motivasi siswa untuk belajar dan juga efektif dalam mencapai kempetensi yang diharapkan.

Pembelajaran dengan mengangkat potensi lokal merupkan pembelajaran yang mengangakat hal nyata di dekat peserta didik. Hal ini sesuai dengan yang diungkapkan [11] bahwa potensi lokal merupakan pembelajaran nyata yang mampu melayani masyarakat dalam memecahkan masalah lingkungan. Beberapa masukan mengenai bahan ajar yang digunakan yaitu mengenai isi matei yang berbasis kearifan lokal sebaiknya disertakan asal daerah atau asal budaya secara detail beserta gambar alat ukur yang dimaksud. Selain itu dietiap latihan soal dan soal/kusi hendaknya diberikan tuntunan jawaban. Pembelajaran berbasis kearifan lokal sangat berpengaruh terhadap prestasi hasil belajar siswa [12]. Siswa sangat terbantu dengan adanya buku ajar berbasis kearifan lokal, sehingga siswa terbiasa dengan apa yang di lihat di lingkungannya [13]. Buku ajar kearifan lokal membuat siswa lebih aktif dan kritis [14].

\section{Kesimpulan}

Pada penelitian ini telah dihasilkan Bahan Ajar Fisika pada Materi Pengukuran Berbasis Kearifan Lokal. Bahan Ajar Fisika pada Materi Pengukuran Berbasis Kearifan Lokal dikatakan sangat layak dengan persentase $78,75 \%$ oleh ahli materi dan sangat layak dengan persentase $77,27 \%$ oleh ahli media. Oleh karena itu secara keseluruhan diketahui bahwa Bahan Ajar Fisika pada Materi Pengukuran Berbasis Kearifan Lokal dikatakan sangat layak digunakan dalam pembelajaran fisika.

\section{Kepustakaan}

[1] Ambarita, Fransiska, "Pengaruh Model Pembelajaran Problem Open Ended dengan Media Handout Terhadap Hasil Belajar Siswa Kelas XI SMA Negeri 12 Medan Tahun Pembelajaran 2015/2016”, FE UNIMED. 2015.

[2] Prastowo, "Pembelajaran Konstruktivistik-Scientific untuk Pendidikan Agama di Sekolah/Madrasah", Jakarta: Raja Grapindo, 2015.

[3] Oktaviana, D., Hartini, S., \& Misbah, M., "Pengembangan modul fisika berintegrasi kearifan lokal membuat minyak lala untuk melatih karakter sanggam”, Berkala Ilmiah Pendidikan Fisika, 5(3), 272-285, 2017.

[4] Yustina, "Pengembangan Booklet pada materi perpindahan kalor untuk meningkatkan kemandirian belajar siswa dikelas X SMA Negeri 1 Nanga Taman”, Pontianak: IKIP PGRI Pontianak, 2018.

[5] I. L. \&. S. S. E. Martiningsih, "Develovment of module based on Scientific Contextual Additive Material to Increase Learning Outcomes and Science Process Skills in Junior High School," Journal of Innovative Science Education, vol. 36, no. 7, pp. 372-381, 2019.

[6] Rosyid, Khakam., "Pengembangan Bahan Ajar Praktik Mata Kuliah Inspeksi dan Tes di Program Studi D3 Teknik Elektro Fakultas Teknik Universitas Negeri Yogyakarta”, Universitas Negeri Yogyakarta, 2019.

[7] Juniati, E., \& Sari, W. P., "Integrasi potensi lokal pada pembelajaran sl terhadap pembentukan learner softskill untuk memecahkan permasalahan lingkungan", Prosiding Symbion (Symposium on Biology Education), Yogyakarta: Universitas Ahmad Dahlan, pp. 545-546, 2016. 
[8] Hartati, S., Misbah, M., \& Resy, R., "Pengembangan modul fisika berintegrasi kearifan local hulu sungai selatan", Jurnal Inovasi dan Pembelajaran Fisika, 4(2), pp. 157-162, 2017.

[9] Widoyoko, E. P., “Evaluasi Program Pembelajaran”, Yogyakarta: Pustaka Belajar. 2016.

[10] Wilujeng, I., Prasetyo, Z. K., \& Suryadarma, I. G. P., Science learning based on local potential: Overview of the nature of science (NoS) achieved, In AIP Conference Proceedings (Vol. 1868, p. 080005), AIP Publishing LLC, 2017.

[11] Retnawati, H., "Validitas dan Reliabilitas dan Karakteristik Butir”, Yogyakarta: Parama Publishing, 2016.

[12] S. R. K. \&. C. S. e. a. Sotiriou, "Introducing Large-Scale Innovation In School," J.Sci.Technol, vol. 67, no. 3, pp. 50-62, 2016.

[13] Tamimiya, K., \& Suryadarma, I., "Potensi lokal Gunung Ijen untuk pemahaman konsep dan berpikir kreatif pengurangan resiko bencana", Jurnal Inovasi Pendidikan IPA, 5(1), 111-128, 2019.

[14] Firdaus, M., \& Wilujeng, I. (2018), "Pengembangan LKPD inkuiri terbimbing untuk meningkatkan keterampilan berpikir kritis dan hasil belajar peserta didik", Jurnal Inovasi Pendidikan IPA, 4(1), 26-40. 